\title{
ANTI-SWAY TRACKING CONTROL OF OVERHEAD CRANE SYSTEM BASED ON PID AND FUZZY SLIDING MODE CONTROL
}

\author{
Le Xuan Hai ${ }^{1}$, Thai Huu Nguyen ${ }^{2, *}$, Tran Gia Khanh ${ }^{3}$, Nguyen Tien Thanh ${ }^{1}$, \\ Bui Trong Duong ${ }^{1}$, Phan Xuan Minh ${ }^{1}$ \\ ${ }^{I}$ Hanoi University of Science and Technology, No 1, Dai Co Viet Street, Hai Ba Trung District, \\ Ha Noi City \\ ${ }^{2}$ Vinh University of Technology and Education, Hung Dung Ward, Vinh City, Nghe An Province \\ ${ }^{3}$ Nam Dinh University of Technology and Education, Phu Nghia Street, Loc Ha Ward, \\ Nam Dinh City, Nam Dinh Province \\ "Email: thainguyenktv@yahoo.com
}

Received: 17 March 2016; Accepted for publication: 26 October 2016

\begin{abstract}
The paper presents a PID - Fuzzy Sliding Mode control (PID-FSMC) algorithm for overhead crane system to guarantee anti-sway trajectory tracking of the nominal plant. The proposed PID-FSMC law guarantees the closed-loop asymptotical stability as well as improve S the transient response of the load sway dynamics when the trolley is moving. The simulation results confirm the propriety of the proposed controller and show great promise of the controller application in practice. Besides, to confirm the controller's application ability, we installed some propositional algorithms into a real system in laboratory.
\end{abstract}

Keywords: anti-sway tracking, PID control, sliding mode control, overhead crane.

\section{PROBLEM STATEMENT}

The problem of anti-sway tracking control for overhead crane system is a common and quite sophisticated one. Therefore, it always attracts the interest of researcher community. In fact, the overhead crane is an underactuated system, i.e., the system has a lower number of actuators than degrees of freedom. This underactuation property leads to the swing of the load and the movement of the trolley. On the other hand, the load dynamics that is out of control may cause insecurity problems in system operation. The problem of anti-sway tracking control for overhead crane systems which have hard nonlinearities and underactuation becomes an urgent need to be continued studying and overcome by researchers. Currently, there are some contributions such as: anti-sway tracking control for overhead crane system in [1]; anti-sway improvement in [2], a nonlinear switching control for 2-D overhead crane system was proposed that uses feedback linearization and Lyapunov stability theory. However, a drawback of the above contributions is that the robustness of the system to changing parameters has not been 
mentioned. Xiao-Jing Wang [3] proposed a robust two-degree of freedom controller which can suppresses the chattering and improve reaching speed. He-Chen [4] also offered a novel braking control method in ensuring trolley braking as long as payload swing suppression, but they are not experimented in a real model. Biao Lu presented a novel nonlinear controller [5] which creates a satisfied quasi exponential convergence of the equilibrium; nonetheless, with many approximations, the theoretical restrictions in the initial conditions are quite strict, the settlement can be improved in the future. Unlike those above methods, with a real model of overhead crane system, Michele Ermidoro [6] introduced a gain scheduled control method to minimize the integral error as long with to constrain the robustness margins, yet the minimization of the settling time is also considered. An adaptive fuzzy sliding-mode control [7] gives a robustness anti-sway trajectory tracking of 2D overhead crane, which is also applied in this paper, but they did not mention to different payloads. Therefore, this paper has proposed the most adequate abilities of the real overhead crane system through defining this one by practically experimental recognitions.

This paper proposes a control law that combines PID and sliding mode strategy to track the reference and reduce the swing of the 2-D overhead crane system. The effectiveness of the proposed PID-FSMC is to track the desired trajectory for the trolley, to resist the load sway when the trolley is moving and the robustness against disturbances and plant-model mismatch. The research results are verified through simulations in Matlab-Simulink and experiments at the laboratory. The paper has 4 parts: Problem Statement, PID-FSMC Synthesis, Numerical Simulations and Experiments, Conclusions.

\section{PID - FSMC}

\subsection{Mathematical Model}

The 2-D overhead crane moves on a track, where $x(t), \theta(t), u(t)$ are the trolley position, sway angle of the load and trolley force, respectively. $M, m, g$ are the trolley mass, load mass and gravity acceleration, respectively, here we omit the cable hardness, the trolley friction, air resistance, outside noise as wind, plastic deformation, etc. as well as mass and the load are considered as a point, the braided cable is used in practice. The system is depicted as in Figure 1.

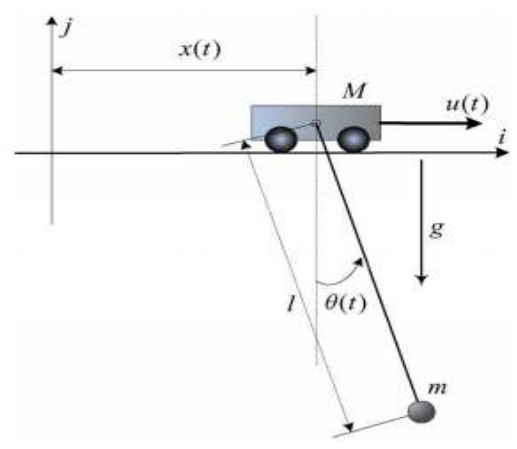

Figure 1. 2-D overhead crane system.

The movement equations of the 2-D overhead crane system are expressed [8] as follows:

$$
\begin{aligned}
& \gamma \ddot{x}+\beta \cos \theta \ddot{\theta}-\beta \sin \theta \ddot{\theta}^{2}=u \\
& \alpha \ddot{\theta}+\beta \cos \theta \ddot{x}-\eta \sin \theta=0
\end{aligned}
$$


where: $\gamma=M+m ; \beta=m l ; \alpha=m l^{2} ; \eta=-m g l$ are model parameters.

\subsection{Controller design}

The anti-sway and tracking PID - FSMC is shown in Figure 2 with two control loops: the inner loop to stabilize the velocity of the trolley by the PI controller and the outer loop is controlled by the PID-FSM controller.

The control system design is divided into 2 steps:

Step 1: Design the tracking PID controller for the outer loop and the PI controller for the inner loop (PID-PI).

Step 2: Design the FSMC for the outer loop (Figure 2).

\subsubsection{The tracking controller}

First of all, the tracking control law for the overhead crane system based on the PID law is depicted as in Figure 3. The outer-loop PID controller then drives the trolley to track the reference while the PI controller has the task to stabilize the velocity and reduce the force that causes the load swinging. The inner-loop PI and outer-loop PID controller designs are performed by PID TOOL in Matlab - Simulink. The advantage of the tool is to allow the design of traditional (PI, PID) controllers to guarantee the desried performance even when the plant model is nonlinear.

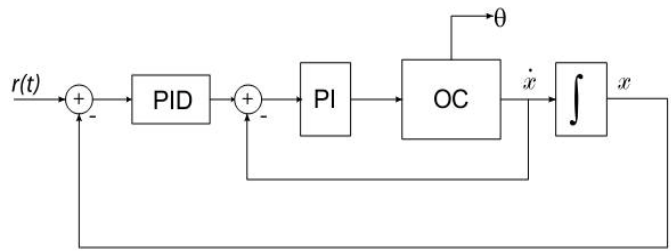

Figure 2. PID - PI Controller.

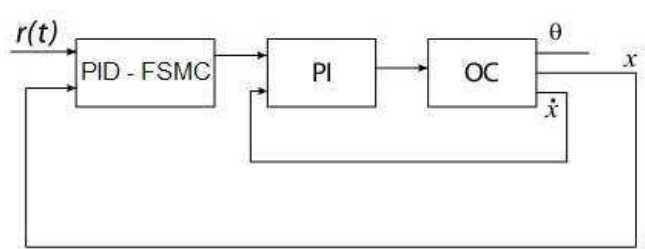

Figure 3. PID - FSMC Controller.

\subsubsection{Sliding Mode Control (SMC)}

Sliding Mode Control is one of the method commonly applied to many controller designs for nonlinear systems, for instance in [9] and [10]. In order to illustrate the method, we consider the following example:

Given a second-order nonlinear system:

$$
\begin{aligned}
& \dot{x}_{1}=x_{2} \\
& \dot{x}_{2}=u+f(x)
\end{aligned}
$$

where $x=\left[\begin{array}{ll}x_{1} & x_{2}\end{array}\right]^{T} \in \mathbb{R}^{2}$ is the state vector, $u \in \mathbb{R}$ is the control signal and $f: \mathbb{R}^{2} \rightarrow \mathbb{R}$ is a nonlinear function. Assume the control objective is to obtain $x_{1}(t) \rightarrow x_{1 \mathrm{~d}}(t)$, let $\tilde{x}=x_{1}-x_{1 \mathrm{~d}}$, we get the sliding surface $s(t)$ as follows:

$$
s(x, t)=\dot{\tilde{x}}+\lambda \tilde{\mathrm{x}}
$$

where $\lambda$ is a positive constant. Differentiate (3) and combine with (2) we get: 


$$
\dot{s}=\ddot{\tilde{x}}+\lambda \dot{\tilde{x}}=\ddot{x}_{1}-\ddot{x}_{1 d}+\lambda \dot{\tilde{x}}=u+f-\ddot{x}_{1 d}+\lambda \dot{\tilde{x}}
$$

Choose $V=\frac{s^{2}}{2} \geq 0, \forall s$, we have:

$$
\dot{V}=s \dot{\mathrm{s}}=s\left(u+f-\ddot{x}_{\mathrm{dd}}+\lambda \ddot{\tilde{x}}\right)
$$

The control signal is chosen to be:

$$
u=-f+\ddot{x}_{1 d}-\lambda \ddot{\tilde{x}}-\eta \operatorname{sgn}(s)
$$

Substitute (6) into (5) we obtain:

$$
\dot{V}=s \dot{s}=-s \eta \operatorname{sgn}(s)=-\eta|s|
$$

For $\eta>0$ we will get $s \rightarrow 0$.

The stability of sliding mode control has the drawback which is known as the chattering phenomenon: when the state trajectory slides on the sliding surface toward the origin, in order to keep it on the sliding surface, i.e., to have $s(t)=0$, the relay $(\operatorname{sgn}(s)$ function) has to continuously switch between -1 to 1 and vice versa with high frequency. The state trajectory then cannot be on the sliding surface but zick-zack around it to make a non-smooth path. In order to reduce this phenomenon, one often uses the saturation to replace the relay:

$$
v= \begin{cases}-\operatorname{sgn}(s) & ,|s| \geq \rho \\ -s & ,|s|<\rho\end{cases}
$$

where $\rho$ is an appropriately chosen range.

The sliding mode controller design can be explained completely from Lyapunov theory to choose the proper function $V=\frac{1}{2} s^{2} \geq 0$, then determine the controller $u$ so that $\dot{V}$ is negative definite.

Apply the sliding mode control law to the overhead crane system in (1) we get:

$$
\ddot{x}=\frac{u+\beta \sin \theta \dot{\theta}^{2}-\beta \cos \theta \ddot{\theta}}{\gamma}=\frac{1}{\gamma} u+\frac{\beta \sin \theta \dot{\theta}^{2}-\beta \cos \theta \ddot{\theta}}{\gamma}
$$

Choose $V(s)=\frac{1}{2} s^{2}>0, s=\lambda e+\dot{e} ; e=x_{d}-x$

Differentiate (10) we get: $\dot{V}=s . \dot{s}$

Let: $\dot{s}=-k \cdot \operatorname{sgn}(s)$ then $\gamma \dot{e}+\ddot{e}=-k \cdot \operatorname{sgn} \Rightarrow \gamma \dot{e}+\ddot{x}_{d}-\ddot{x}=-k \cdot \operatorname{sgn} s$

$$
\begin{aligned}
& \Rightarrow \gamma \dot{e}+\ddot{x}_{d}-(g(x) u+f(x))=-k \cdot \operatorname{sgn} s \\
& \Rightarrow u=\frac{\lambda \dot{e}+\ddot{x}_{d}-f(x)+k \cdot \operatorname{sgn} s}{g(x)} \Rightarrow u=\lambda \gamma \dot{e}+\ddot{x}_{d} \gamma+\gamma k \cdot \operatorname{sgn} s-\beta \sin \theta \theta^{2}+\beta \cos \theta \ddot{\theta}
\end{aligned}
$$

where: $u$ is the sliding control signal. Since $\theta$ is very small then we have $\sin \theta=\theta$ and $\cos \theta=1$

The reference trajectory in [11] is used with the velocity profiles having both acceleration and deceleration zones as follows:

$\dot{x}_{d}(t)=\frac{v_{\max }}{2}\left(1-\cos \left(\frac{\pi}{t_{a}} t^{*}\right)\right), \quad 0 \leq t \leq t_{a}$ 


$$
\dot{x}_{d}(t)=\frac{v_{\max }}{2}\left(1-\cos \left(\frac{\pi}{t_{a}} t^{*}\right)\right), t_{a}+t_{c} \leq t \leq t_{d} ; \lambda=10 ; k=1
$$

In order to improve the performance of the overhead crane control system, i.e., to reduce the payload swing while tracking the reference, we propose to employ the combination of PIDFSMC

\subsubsection{Fuzzy Sliding Mode Control}

First of all, we introduce two fuzzy sets of the sliding surface $\chi_{\theta}$, which are $X_{\theta}^{I B} \triangleq\left\{\chi_{\theta} \in R|k(t) \cdot| \chi_{\theta} \mid<\phi\right\}$ and $X_{\theta}^{O B} \triangleq\left\{\chi_{\theta} \in R|k(t) \cdot| \chi_{\theta} \mid>\phi\right\}$. Here, the positive constant $\phi$ depicts the boundary layer, the time function $k(t)$ is the scale of the time-varying cancellation of the boundary layer, IB and OB stand for the boundary layer and outer boundary. The family of fuzzy set function is selected from [7] and shown in Figure 4:

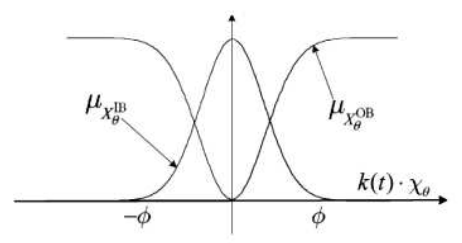

(a)

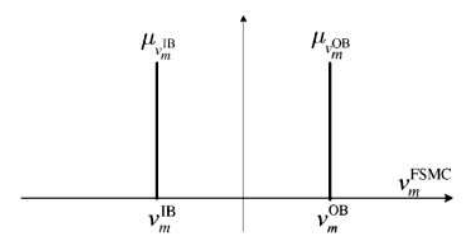

(b)

Figure 4. Family of fuzzy set functions in FSMC.

The functions in the above two fuzzy sets are determined as follows:

$$
\begin{aligned}
& \mu_{X \theta}^{I B}(\chi \theta) \triangleq e^{\left(\frac{k(t) \cdot \chi \theta}{\lambda \cdot \varphi}\right)^{2}} \\
& \mu_{X \theta}{ }^{B B}(\chi \theta) \triangleq 1-\mu_{X \theta}^{I B}(\chi \theta)
\end{aligned}
$$

where: the positive constant $\lambda$ is small enough to make the value of $\mu_{X \theta}^{I B}(\chi \theta)$ approximately equal to zero form the boundary of the set $\left(\left|\chi_{\theta}\right| \geq \phi\right)$. Moreover, the control law is given by:

$$
\begin{aligned}
& v_{m}^{I B}=v_{m}^{d} \\
& v_{m}^{O B}=\left|\chi_{e}\right| \cdot \operatorname{sgn}\left(\chi_{\theta}\right)+v_{m}^{d}
\end{aligned}
$$

where: $v_{m}^{d} \triangleq k_{\theta d} \dot{\theta}+\left(k_{g}-1\right) g_{c} \sin \theta$ and $k_{g}>1$ is constant. Assume the basic of the fuzzy control law is:

Law 1: If $\chi^{\theta}$ is $\mathrm{X}_{\theta}^{\mathrm{IB}}$, then $v_{m}^{F S M C}$ is $v_{m}^{I B}$

Law 2: If $\chi^{\theta}$ is $\mathrm{X}_{\theta}^{\mathrm{OB}}$, then $v_{m}^{F S M C}$ is $v_{m}^{O B}$

where: only $v_{m}^{I B}$ and $v_{m}^{O B}$ are numbers shown in Figure 3, i.e., $\mu_{v_{m}^{i}}=1$ if $v_{m}^{F S M C}=v_{m}^{i}$ and $\mu_{v_{m}^{i}}=0$ in contrast with $i=I B$ and $O B$. Then, a fuzzy inference system, a fuzzy controller and a FSMC law which serves as the fuzzy system output using defuzzifier, a minimum inference engine and singleton fuzzifier [12] is rewritten as follows: 


$$
v_{m}^{F S M C}=\frac{\mu_{X \theta}^{O B}\left(\chi_{\theta}\right) v_{m}^{O B}+\mu_{X \theta}^{I B}\left(\chi_{\theta}\right) v_{m}^{O B}}{\mu_{X \theta}^{O B}\left(\chi_{\theta}\right)+\mu_{X \theta}^{I B}\left(\chi_{\theta}\right)}
$$

Substitute (8) by (9), it can be expressed as:

$$
v_{m}^{\text {FSMC }}=\left|\chi_{e}\right| \cdot \operatorname{sgn}\left(\chi_{\theta}\right) \cdot \mu_{X_{\theta}^{O B}}\left(\chi_{\theta}\right)+v_{m}^{d}
$$

Equation (15) shows that $v_{m}^{\text {FSMC }}$ consists of a new resistance component $v_{m}^{d}$ and a fuzzy switching component $\left|\chi_{e}\right| \cdot \operatorname{sgn}\left(\chi_{\theta}\right) \cdot \mu_{X_{\theta}^{0 B}}\left(\chi_{\theta}\right)$. The operation of the fuzzy switching is to make the control process easier. Moreover, the new resistance component $v_{m}^{d}$ improves the load anti-sway action. Therefore, the combination of PID and FSMC will form an anti-sway trajectory tracking controller for the 2-D overhead crane system in Figure 2. Thus the parameters to be determined for this combination are the PID parameters and $v_{m}^{F S M C}$.

\section{NUMERICAL SIMULATIONS AND EXPERIMENTS AT THE LABORATORY}

Given the system parameters

$$
M=1.0731(\mathrm{~kg}) ; m=0.23(\mathrm{~kg}) ; l=0.64(\mathrm{~m}) ; g=9.8\left(\mathrm{~m} / \mathrm{s}^{2}\right)
$$

\subsection{PI-PID control}

The overhead crane is a nonlinear system with uncertainty. We therefore employ the experimental method to determine the traditional PID parameters with: $K_{p}=1, K_{i}=0.1, K_{d}=3 ; P I: K_{p}=5, K_{i}=0.01$

The simulation results of the trolley and sway angle using PI-PID:

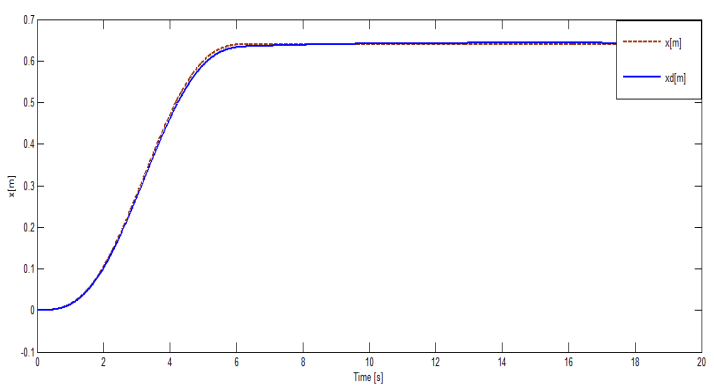

Figure 5. Trolley trajectory as a function of time.

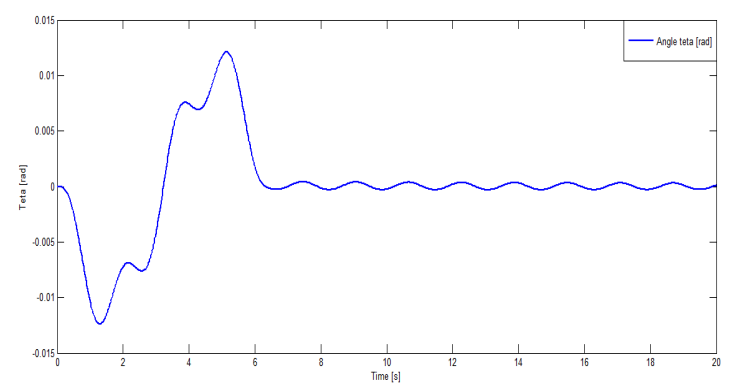

Figure 6. Load sway angle as a function of time.

Figure 5 and 6 show the position of trolley and the angle of load. The simulation results are implimented on computer by Matlab/Simulink software with PID controller

The simulation results of the trolley and sway angle using SMC: 


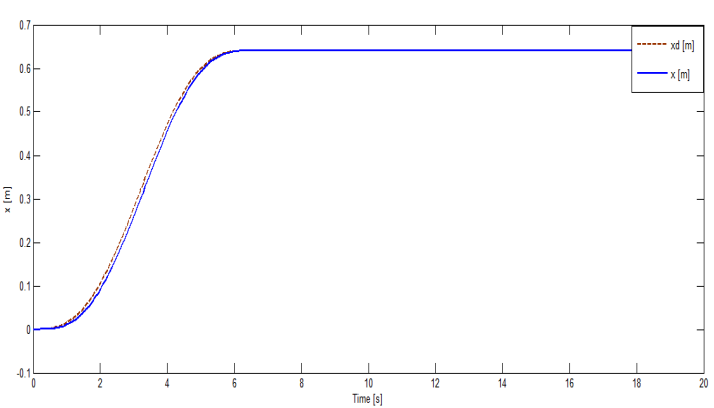

Figure 7. Trolley trajectory as a function of time (SMC).

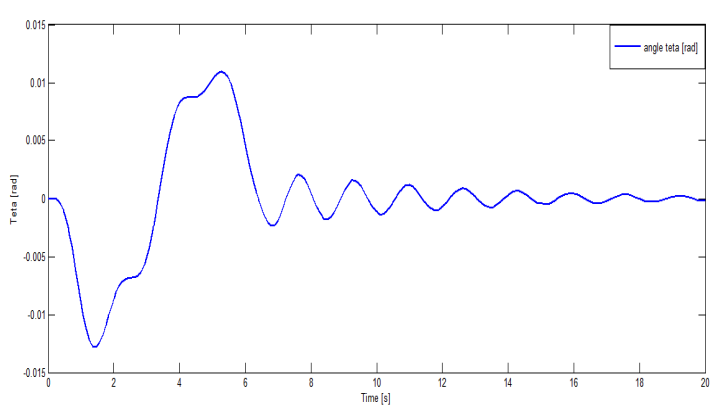

Figure 8. Load sway angle as a function of time

(SMC).

Figure 7 and 8 show the position of trolley and the angle of load. The simulation results are implimented on computer by Matlab/Simulink software with SMC controller

The simulation results of the trolley and sway angle using PID-FSMC:
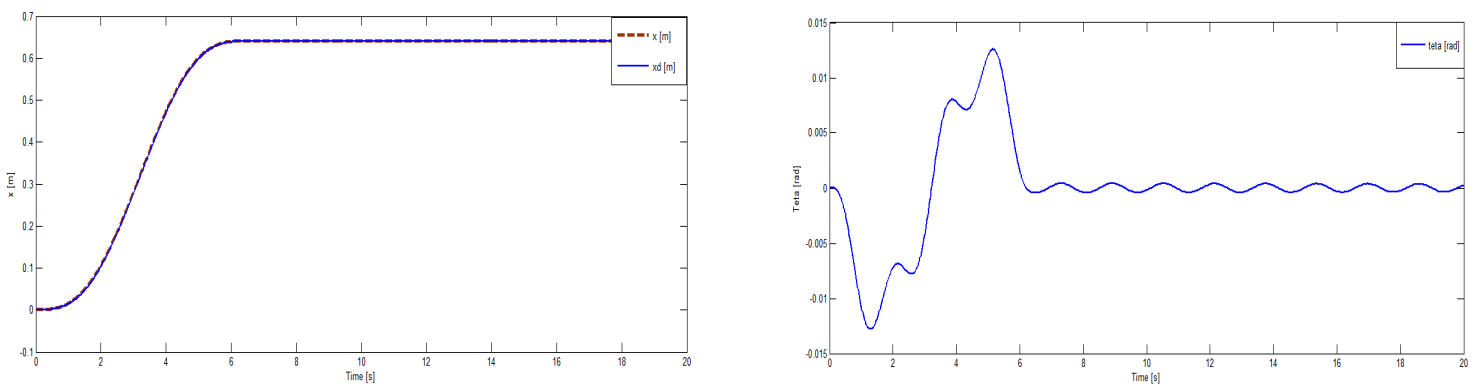

Figure 9. Trolley trajectory as a function of time. Figure 10. Load sway angle as a function of time.

Figure 9 and 10 show the position of trolley and the angle of load. The simulation results are implimented on computer by Matlab/Simulink software with PID-FSMC controller

\subsection{Compare the results}

The quality of position control of three proposed controllers is shown in the same coordinate system using Matlab/Simulink as in Figure 11 and Figure 12:

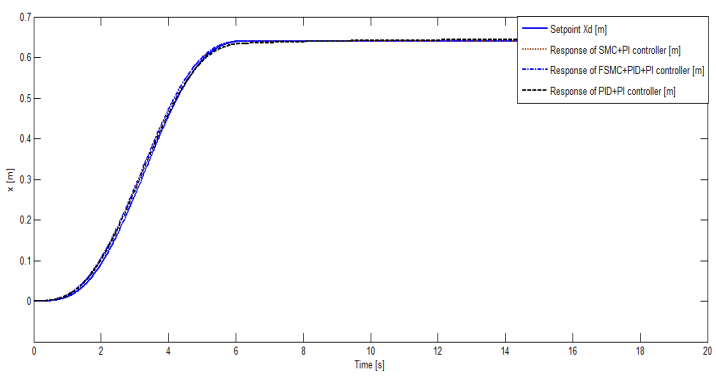

Figure 11. Trolley trajectories with 3 controllers.

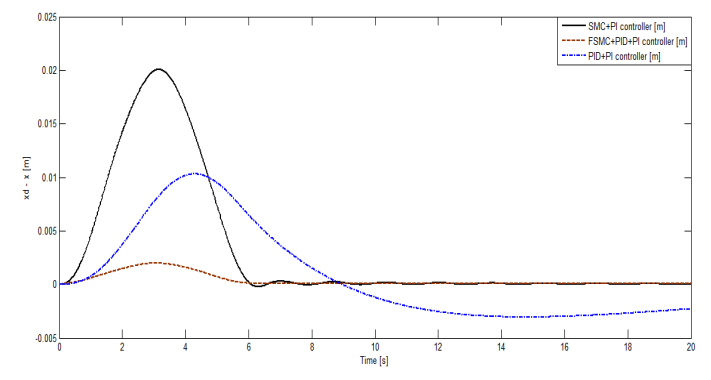

Figure 12. Comparisons between $x_{d}$ và $x$ with 3 controllers.

The quality of angle control of three proposed controllers is shown in the same coordinate system using Matlab/Simulink as in Figure 13

In order to prove the ability of proposed PID-FSMC method, the simulation with the changing of load is used for simulation and the results are shown as. 


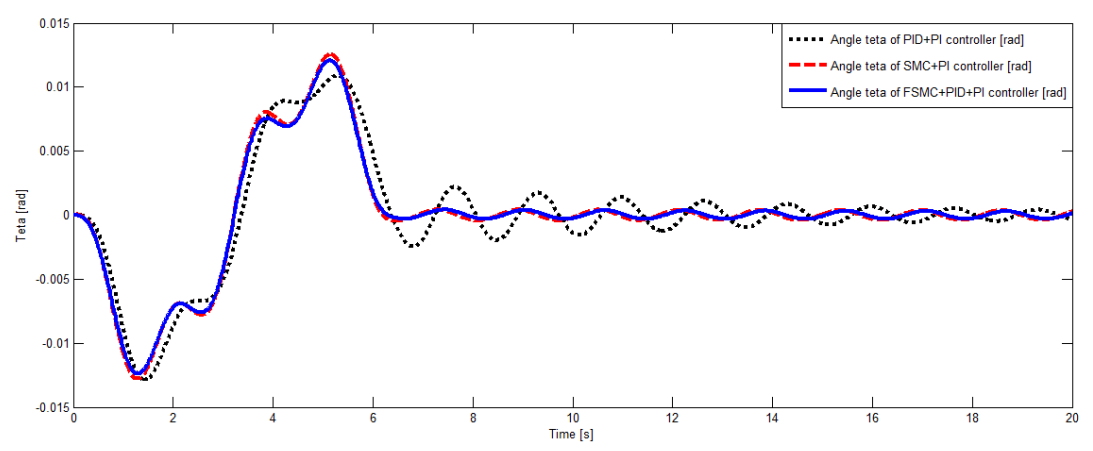

Figure 13. Load sway angle with 3 controllers.

\subsection{Controller simulation results}

Figure 14 and 15 show the position of trolley and the angle of load mass $m=0.3 \mathrm{~kg}$, the simulation results are implimented on computer by Matlab/Simulink software with PID-FSMC controller.

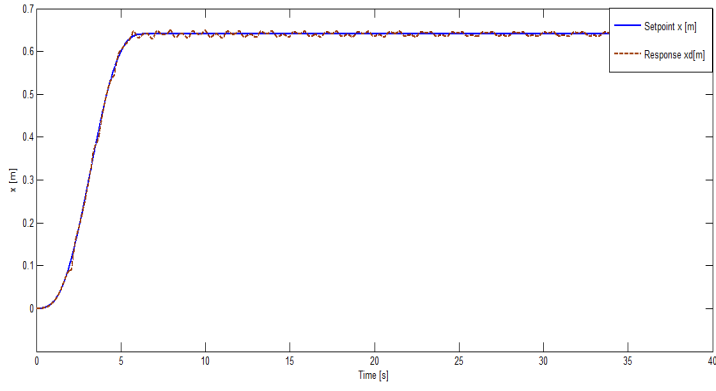

Figure 14. Trolley position with load mass $m=0.3(\mathrm{~kg})$ using PID-FSMC.

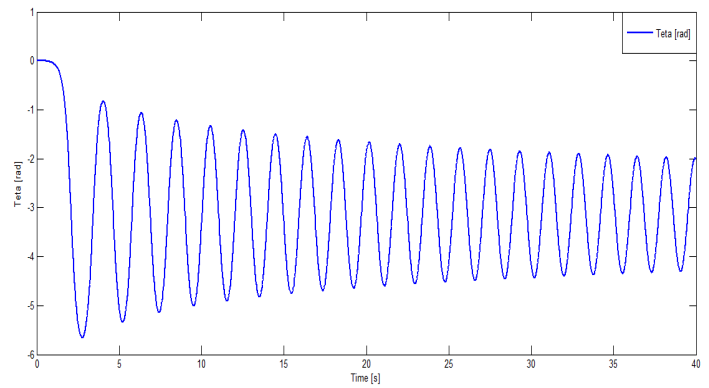

Figure 15. Load sway angle with load mass $\mathrm{m}=0.3(\mathrm{~kg})$ using PID - FSMC.

Figure 16 and 17 show the position of trolley and the angle of load mass $\mathrm{m}=0.4 \mathrm{~kg}$, the simulation results are implimented on computer by Matlab/Simulink software with PID-FSMC controller.

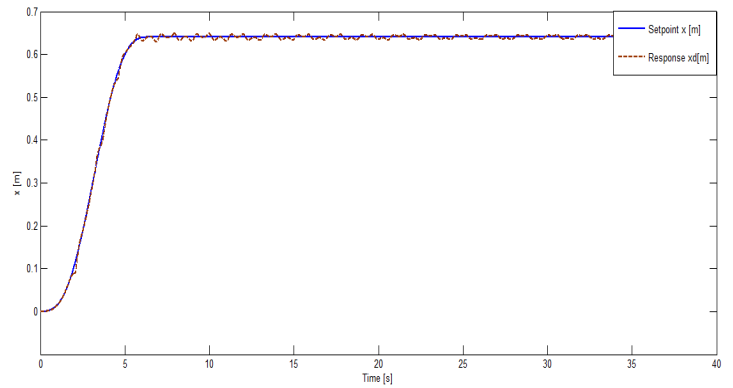

Figure 16. Trolley position with load mass $\mathrm{m}=0.4(\mathrm{~kg})$ using PID-FSMC

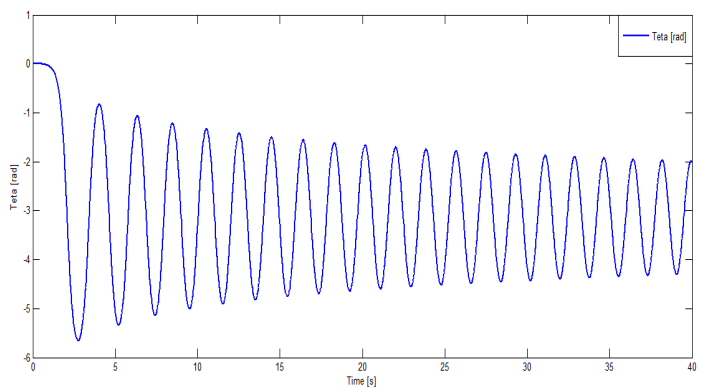

Figure 17. Load sway angle with load mass $\mathrm{m}=0.4(\mathrm{~kg})$ using PID-FSMC 
From the experiment results, we conclude that the controller still works well in some range of load mass. For other load mass and strategy, we will simulate in other paper.

The simulation results show that the errors tend to zero after 20 seconds, the trolley tracks the trajectory during the simulation time, the system performance with PID-SFMC is much better than that with PID control, Sliding mode control with the reduction of load sway angle. On the other hand, the performance of the control system is still excellent with the variations of load mass, the trolley position follows the trajectory within the simulation time and the sway angle is very small.

\subsection{Controller experiment results}

\subsubsection{The 3D overhead crane in laboratory}

The 3D overhead crane in laboratory as a fllowing model (Figure 18) in [13]:

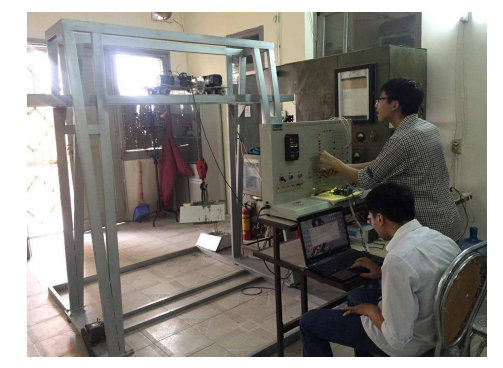

Figure 18. The 3D overhead crane in laboratory.

The controller is developed on the microcontroller ATMEGA32 with the sampling time of 25 (ms). The program is written in $\mathrm{C}$ and implemented into the microcontroller utilizing the ISP 89S/AVR via USB.

Human Machine Interface (HMI) is designed with the following functions:

- Provide set-point for the position of the trolley

- Display the position and speed of the trolley, the swing angle of payload and its derivative.

- It is written in C\# programming, the HMI screen is shown in Figure 19:

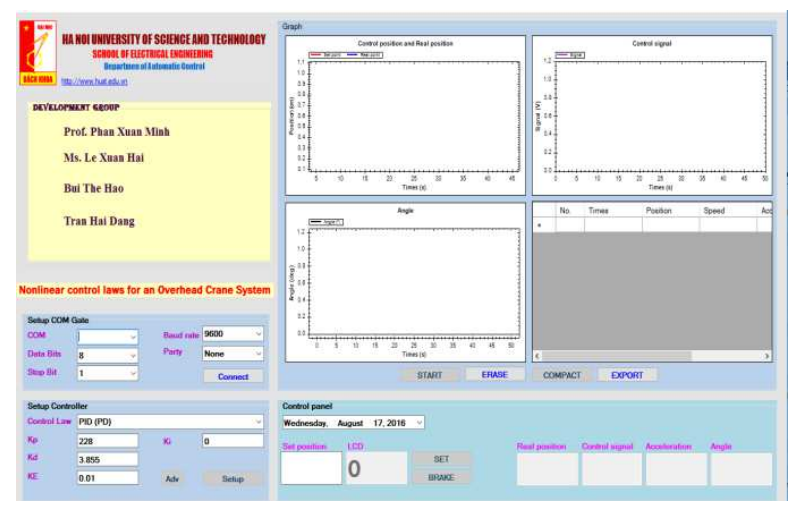

Figure 19. Human Machine Interface. 
The HMI consists of three major parts:

Part 1: Enter the position of the trolley, select type of controllers and controller parameters

Part 2: Display the real position of the trolley, control signal and swing angle of the payload in number. in $\mathrm{cm}$ )

Part 3: Plots for position set-point, real positions ( $x$ axis is time in second, y axis is position

\subsubsection{Experimental parameters}

Mass of trolley $(6 \mathrm{~kg})$, mass of payload $(5 \mathrm{~kg})$, length of rod $(0.7 \mathrm{~m})$. Experimental results with the proposed method as follows and its image at laboratory is shown in Figure 20:

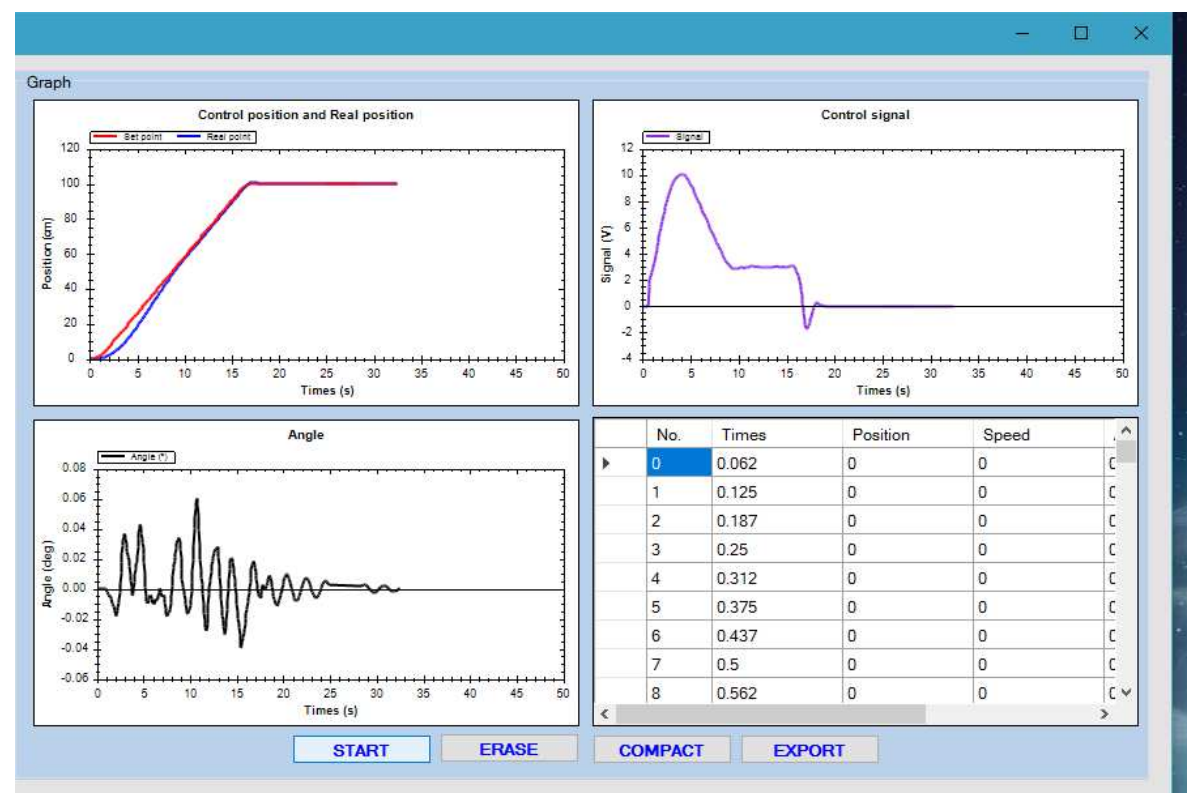

Figure 20. Real position, control signal and swing angle with set position (1 m).

From the experimental results, it can be seen that:

- The settling time is about.

- Control signal without disturbance.

- Existence of small overshoot.

- Capacity of tracking the sliding surface.

- Swing angle is from -0.04 to 0.06 degree and it tends to zero.

Through experimental results with real system, it can be concluded that the sliding fuzzy PID guarantees trajectory tracking of the trolley and ability to anti-swing well and prove the application of the proposed method in industry. 


\section{CONCLUSIONS}

This paper presented a trajectory tracking controller for 2-D overhead crane system using PID-FSMC. The simulation results show that the system satisfies the required performances such as trolley trajectory tracking, reasonable settling time and load anti-sway. However, these results are obtained from the approximated model (1) with small sway angle. Experimental results proved that the application of the controller is possibly well applied in industry.

\section{REFERENCES}

1. Fang Y., Dixon W., Dawson D. and Zergeroglu E. - Nonlinear coupling control laws for an underactuated overhead crane system, IEEE/ASME Trans. Mechatronics 8 (3) (2003) pp. 418-423.

2. Park H., Chwa D. and Hong K. S. - A feedback linearization control of container cranes: Varying rope length, Int. J. Control Autom. Syst 5 (4) (2007) pp. 379 - 387.

3. Wang X. J. , Chen Z. M. - Two degree of freedom sliding mode anti-swing and positioning controller for overhead crane, IEEE (2016).

4. Jong H. C., Fang C. - A novel Emergency braking method with payload swing suppression for overhead crane system, Springer International Publishing Switzerland (2016).

5. Fang B. J., Sun N. - A new sliding mode like nonlinear controller for overhead crane with smooth control inputs, American Control Conference (2016).

6. Miche E., Simone F., Fabio P. - Fixed order gain scheduling anti-sway control of overhead bridge cranes, Mechatronics (2016).

7. Park M. S., Chwa D. and Hong K. S. - Anti-sway tracking control of overhead cranes with system uncertainty and actuator nonlinearity using an adaptive fuzzy sliding mode control, IEEEE (2008).

8. Yang J. H. and Yang K. S. - Adaptive coupling control for overhead crane systems, Mechatronics 17 (2/3) (2007) pp. 143 - 152.

9. Phuoc N. D., Minh P. X., Han T. T. - Nonlinear control theory, Publisher of Science and Technique (2008).

10. Phuoc N. D. - Analysis and control nonlinear System, Publisher of encyclopedia (2012).

11. Lee H. - Motion planning for three-dimensional overhead cranes with high-speed load hoisting, Int. J. Control 78 (12) (2005) pp. 875 - 886.

12. Wang L. - A Course in Fuzzy Systems and Control, Englewood Cliffs, NJ: Prentice-Hall (2006).

13. Hai L. X., Thai N. V., Duong B. T., Nga V. T. T., Nguyen T. H., Minh P. X. Implementation of a laboratory overhead crane control, Journal of scientific research and military technology No14 (August 2016). 


\title{
TÓM TẮT
}

\section{ĐIỀU KHIỂN BÁM CHỐNG LẮC CHO CẦN CẨU TREO TRÊN CƠ SỞ KẾT HỢP ĐIỀU KHIỂN PID VÀ ĐIỀU KHIỂN TRƯợT MỜ}

\author{
Lê Xuân Hải ${ }^{1}$, Thái Hữu Nguyên ${ }^{2,}{ }^{*}$, Trần Gia Khánh ${ }^{3}$, Nguyễn Tiến Thành ${ }^{1}$, \\ Bùi Trọng Dương ${ }^{1}$, Phan Xuân Minh ${ }^{1}$ \\ ${ }^{1}$ Truờng Đại học Bách khoa Hà Nội, Số 1, Đường Đại Cồ Việt, Quận Hai Bà Trunng, Hà Nội \\ ${ }^{2}$ Trưòng Đại học Su phạm Kỹ thuật Vinh, Phường Hưng Dũng, Thành Phố Vinh, \\ Tỉnh NghệAn \\ ${ }^{3}$ Trương Đại học Su phạm Kỹ thuật Nam Định, Đương Phù Nghĩa, Phương Lộc Hạ, \\ Thành phố Nam Định, Tỉnh Nam Định \\ "Email: thainguyenktv@yahoo.com
}

Bài báo trình bày về một thuật toán điều khiển PID - trượt mờ (PID-FSMC) cho cần cẩu treo nhằm đảm bảo cho việc bám quĩ đạo chống lắc của đối tượng. Luật điều khiển được đề xuất này là sự kết giữa điều khiển PID và FSMC đảm bảo hệ kín ổn định tiệm cận, bám quỹ đạo đồng thời giảm rung lắc của tải khi xe chuyển động. Các kết quả mô phỏng và cài đặt thực nghiệm khẳng định tính đúng đắn của bộ điều khiển được đề xuất và mở ra khả năng ứng dụng của bộ điều khiển trong thực tế.

Từ khóa: bám quỹ đạo chống rung lắc, điều khiển PID, điều khiển trượt mờ, cần cẩu treo. 